\title{
Optimization of Naphtha Hydro-Threating Unit with Continuous Resuscitation Due to the Optimum Temperature of Octanizer Unit Reactors
}

\author{
Amir Samimia, (iD, Soroush Zarinabadib,*, Amir Hossein Shahbazi Kootenaeia, Alireza Azimia, \\ Masoumeh Mirzaeia
}

${ }^{a}$ Department of Chemical Engineering, Mahshahr Branch, Islamic Azad University, Mahshahr, Iran

${ }^{b}$ Department of Engineering, Ahvaz Branch, Islamic Azad University, Ahvaz, Iran

\section{ART I CLE I N F O}

Received: 10 June 2019

Revised: 4 July 2019

Accepted: 20 August 2019

Available online: 22 August 2019

\section{K E Y W O R D S}

\section{Gasoline}

Petrochem software

Temperature

Naphtha hydrogen purification

Catalyst chloride

\section{A B S T R A C T}

In this study, the processes led to the production of gasoline and reactions resulting in increasing the octane number in the catalytic conversion unit with continuous resuscitation has been described first then simulated with Petrochem software. Considering all the research and investigations, the best recommended values of operational variables for producing high quality gasoline at nominal capacity has been achieved to account for temperature 525 degrees centigrade in the reactors input, flow rate of 22 tons per hour with $93 \%$ hydrogen purity, pressure 5.5 relative bar of the circulating gas compressor output, concentration of 0.9 percent weight of catalyst chloride, Naphtha hydrogen purification unit which resulted in the production of 25630 gasoline barrels per day and 0.37 volume percent benzene that the mass efficiency of the catalytic converter.

\section{GRA P H I C A L A B S T RACT}

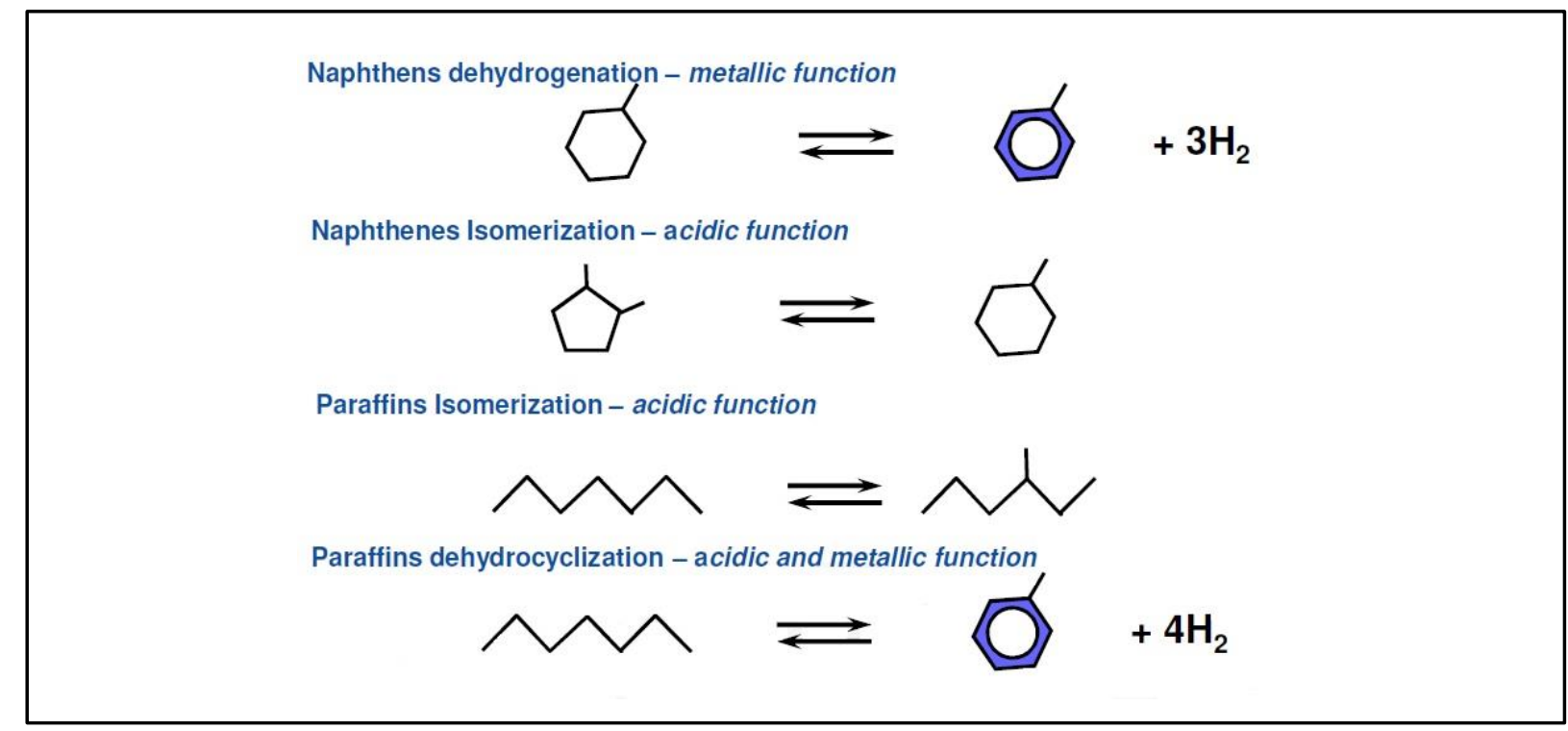

* Corresponding author's E-mail address: soroushzarinabadi@iauahvaz.ac.ir 


\section{Introduction}

The dependence of advanced countries on petroleum products, especially gasoline and the outbreak of petroleum crises in the $1970 \mathrm{~s}$ due to the increasing and overcoming consumption on production and extraordinary rise in petroleum prices and its products, urged industrialized countries to deal with energy problem and take a different approach [1-4]. Undoubtedly, the importance of the strategic product, gasoline in terms of current conditions, quality and quantity dimensions is not covered on everyone with respect to the growing demand of the country and the growth of imports and further dependence and the spread of environmental pollution and the prevalence of various diseases caused by pollution and the low quality of existence gasoline [5-7]. One of the most important properties and quality features of a high quality gasoline product is also low levels of pollutants such as sulfur, benzene, and aromatic compounds such as sulfur, benzene, and aromatic compounds and lead and manganese particles from environmental standards, octane number of the fuel [8]. The higher the octane number is, the fuel is more resistant to combustion, pressure and heat. Basically, the octane number is a measure to indicate the gasoline resistance to the heat, push and start of spontaneous combustion. In Naphtha hydrogen purification unit, impurities such as sulfur and nitrogen which cause catalyst poisoning in the downstream catalytic units, are excluded from the gross Naphtha. This process is carried out by gross Naphtha passing of a catalytic bed in adiabatic reactor using hydrogen gas. The product of this light and heavy Naphtha unit has been split and the design capacity of this unit is 60000 barrels per day. In the catalytic conversion unit, continuous recovery has caused the reaction and catalytic conversion in the high temperature and low pressure by a slow passing of heavy Naphtha from a catalytic bed of three Adiabatic reactor using hydrogen and a layer of coke is formed on a catalytic bed. Therefore, the catalyst is constantly being recovered and restored in this unit. The main product of this unit have been gasoline with octane number 95 and its by-product, petroleum gas [9-13].

\section{Research background}

In 1940, Dr. Vladimir Haensel, chemistry engineer researcher at UOP (Universal Oil Product Company) of America developed the Naphtha catalytic conversion by using a platinum containing catalyst for the first time. Dr. Haensel proposed the use of small platinum metal particles on the alumina surface acid base to conduct chemical reactions in order to optimize and gasoline octane number improvement after much research in 1947 [14]. Subsequently, in 1949, Dr. Hansel's process has become commercial on industrial scale by UOP Company to produce gasoline with a high octane number from Naphtha and this process of UOP Company is known as plat forming process in the world [15]. The first plat forming unit of Naphtha was built in 1949 at the old Dutch oil refinery, Michigan, United States and in this way, the catalyst conversion reforming process was functionally and industrially introduced and developed during 1947 to 1949 [16-19]. The completion and development of these processes continued in the coming years until in the end, it has resulted in the introduction of the final design model of Naphtha catalytic conversion with an animated bed for its continuous resuscitation. After that, by modifying the catalyst used by the catalytic conversion reforming process, its performance was more optimized [20-24].

Marton I. et al., (2013), in another paper on RAP refinement asphalt, used the decision tree algorithm to analyze the available data. The results indicate that choosing a balanced mix design is dependent on the selection of 
appropriate levels of RAP content and binding rating to the application conditions in terms of temperature and loading density [25].

Mazloumi E. et al., (2011), Using the C-Tree software, which is a non-parametric class of regression trees, well describes regression organisms in a theory, the Conditional Inference Method examines existing problems. This applies to all types of regression, including nominal, row, numeric, and censored variables, as well as several variables and arbitrary scale measurements of private [26-29].

Xiaoyong G. (2018) [30-34] shows that increasing of refinery scheduling attracts in some petrochemical companies and universities during these days. Due to this article to the petrochemical complexes of industries some informations have been reported for better use in all of the world. They have also proposed new way to exploit the prior knowledge existing in industries, and increased a new decision making system to help the scheduling process.

Marton I. et al., (2013), in another paper on RAP refinement asphalt, used the decision tree algorithm to analyze the available data [13]. The results indicate that choosing a balanced mix design is dependent on the selection of appropriate levels of RAP content and binding rating to the application conditions in terms of temperature and loading density [35-36].

\section{Experimental}

Data collection and storage technologies have made it possible for organizations to extract a large amount of data in the shortest possible time. The exploitation of this stored data, in order to extract useful and practical information, is the general purpose of the public activity known as data mining. Data mining the process of discovery and analysis, either automatically or semi-automatic, is of greatly high value in order to discover meaningful patterns and rules. Data mining is an interdisciplinary branch of computer science that involves the discovery of patterns from a large set of data. The purpose of this advanced analysis process is to extract information from a dataset and turn it into an understandable structure for later use. The methods used are a combination of artificial intelligence, machine learning, statistics, and database systems and business intelligence.

\section{Process of Naphtha hydro-treating (NHT) unit}

The goal of the Naphtha hydro-treating (NHT) unit is to produce clean and refined feed for the supply of Octane and Isomerization units. The feeds of these units should have the lowest amount of pollutants such as sulphur, nitrogen, water, halogens, diolefins, olefins, arsenic, mercury and other metals, so that the efficiency of the lower units, especially the catalyst, is not affected by these units. The feed of the NHT can be HRSG produced by upstream units (distillation units) or a mixture of Heat Recovery Steam Generation (HRSG) and Naphtha produced by the concentration units of the breaker or Isomax units. All of these cuts can have different levels of superpollution, which is catalytic converting and isomerization catalytic converters, and therefore hydrogen refining operations are essential. The process of NHT is carried out in a reactor in the presence of a nickelmolybdenum bimetallic catalyst and in the presence of hydrogen. The temperature is relatively high (about $270{ }^{\circ} \mathrm{C}$, the temperature should be more than $250{ }^{\circ} \mathrm{C}$ which reaction would be started) required for the process to be performed. After chemical reactions, Naphtha is subjected to buckling operations to separate hydrocarbon and gas components including hydrogen sulphides H2S and water. Then, the oil cut in the separating tower (Splitter tower) is divided into two distinct sections 
for feeding the isomerization unit (Light Naphtha) and the Octanizer unit (Heavy Naphtha). Surprisingly the high efficiency of the octane units and isomerization depends greatly on the efficiency and efficiency of the Naphtha purification unit. The maximum limit for sulphur and nitrogen contamination in the refined feed unit is 0.3 ppm and the final limit of contamination such as lead, copper, silica, nickel, chromium is less than ppb 5 .

Simulation the purification process of
Naphtha hydro treating unit in gasoline complex

The most important need to form and define a single-feed oil certificate is the experimental results of the feed curve that has been used the average values of the refinery lab results to increase the accuracy in this study. The average values of the laboratory distillation diagram results are shown as volume percentage and based on distillation ASTM D86 standard method in Table 1.

Table 1. Average values of ASTM D86 distillation curve results the feed of purification of Naphtha hydro treating based on volume percentage-degree centigrade

\begin{tabular}{ccc} 
Name & Data & The unit \\
Density & 0.7208 & - \\
Initial boiling point (IBP) & 44.02 & ${ }^{\circ} \mathrm{C}$ \\
$5 \%$ & 63.43 & ${ }^{\circ} \mathrm{C}$ \\
$10 \%$ & 70.43 & ${ }^{\circ} \mathrm{C}$ \\
$30 \%$ & 87.15 & ${ }^{\circ} \mathrm{C}$ \\
$50 \%$ & 104.07 & ${ }^{\circ} \mathrm{C}$ \\
$70 \%$ & 124.31 & ${ }^{\circ} \mathrm{C}$ \\
$90 \%$ & 142.17 & ${ }^{\circ} \mathrm{C}$ \\
$95 \%$ & 156.27 & ${ }^{\circ} \mathrm{C}$ \\
Final boiling point (FBP) & 163.18 & ${ }^{\circ} \mathrm{C}$ \\
\hline
\end{tabular}

Figure 1. The first section of informations and laboratory values and Naphtha feed properties related to NHT feed certificate in simulated software

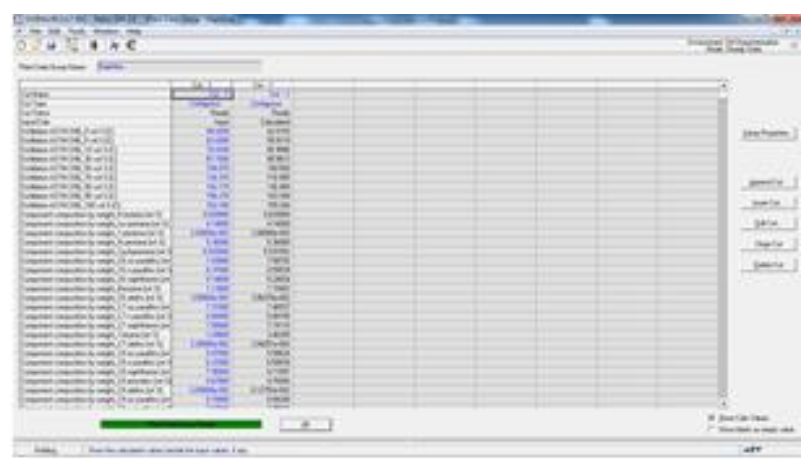

equation provides a good accuracy for many systems in a wide range of conditions and often solves the single - phase, two - phase and threephase systems with a high and reliable efficiency. As seen in Figure 1,2, the differences
It is noted that Peng Robinson Equation of State was used to simulate this project for applications of oil, gas and petrochemical processes, this equation state is commonly used as a package of thermodynamic properties. This 
between software calculations and actual laboratory values of the single feed oil profile input were very low which indicates the high accuracy of the laboratory data collected by the aforementioned oil certificate.

As can be seen, the number of defined properties of the Naphtha feed cut is 41 in this oil form.

Simulation of a three-phase separator container related to a separating tower feed

The purpose of the three phase separator simulation is to form a current flow input feed the separating tower of purification of Naphtha hydro treating unit. In this unit the input flow of three - phases separator is a mixture of Naphtha input feed and returned gas flow and supply water to the boiler. Naphtha feed sulfur is converted to hydrogen sulfide in the reactor that the amount of hydrogen sulphides in this current is equal to the amount of hydrogen sulphides in the returned gas of purification of Naphtha hydro treating unit. It is necessary to explain that in the purification of Naphtha hydro treating unit, water supply boiler is injected into the reactor output heat exchangers tubes to prevent sedimentation of mineral salts. The amount of current flow of the purification of Naphtha hydro treating unit of flow transmitter controller is $213 / 11$ ton per hour. The flow of input Naphtha feed into the mixer has been determined and specified according to the oil certificate profile in the previous section. The amount of input returned gas flow into the mixer should be determined how the output gas flow from the top of the simulated three - phases separator will be equal to the average flow of returned gas of flow transmitter: 9510 kilo gram per hour [37-39]. The mixture of returned gas compounds percentage of purification of Naphtha hydro treating unit is considered based on average values of laboratory collected informations in Table 2. The separator pressure is 19 relative bar and its temperature is 49 degrees centigrade.

Figure 2. The second section of informations and laboratory values and Naphtha feed properties related to NHT feed certificate in simulated software

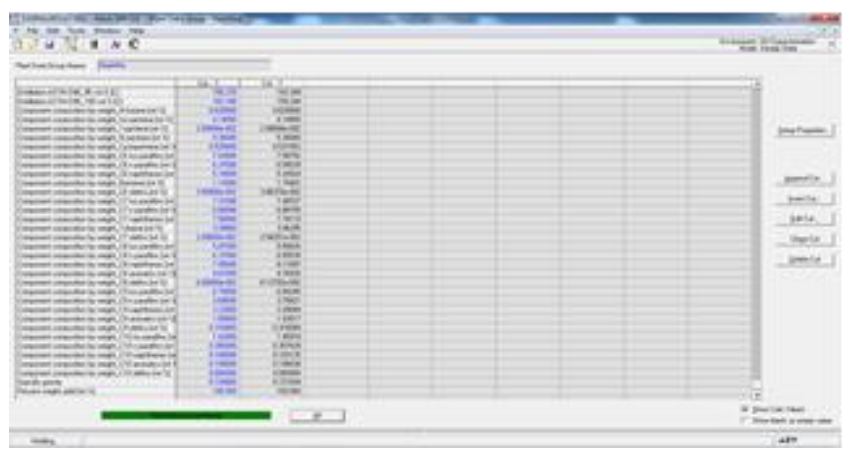

Table 2. Average values of mixture of returned gas percentage of purification of Naphtha hydro treating unit

\begin{tabular}{cc} 
Components & $\% \mathrm{Mol}$ \\
Hydrogen & 87.25 \\
Methane & 6.1 \\
Ethane & 0.42 \\
Propane & 0.3 \\
Iso Butane & 0.19 \\
Normal Bhutan & 0.67 \\
ISO Pentane & 1.64 \\
Normal Pentane & 1.66 \\
Nitrogen & 1.89 \\
Hydrogen Sulfide & 0.0801 \\
\hline
\end{tabular}


Figure 3. The simulation of three-Phase separator of separating tower feed of purification of Naphtha hydro treating unit
Simulation of separating tower section of purification of Naphtha hydro treating unit

First, the heat convertor must be installed before the separating tower feed heater. Feed flow is entered into the tubes and the pressure difference of the tubes in the convertor based on evidence is 3.2 bar. This current heated up and enters the tower during a thermal exchange with the flow of a liquid from the bottom of the tower that enters the shell. The pressure difference in the shell sector is 1.4 bar according to the documents. In order to simulate the heat convertor, the final point method will be used and the surface value and the overall heat transfer coefficient will be imported. The important point is that since the separating tower is not simulated yet, the input current is not present to the converter shell and it is required to solve the converter. In order to overcome this problem, temporarily, the input flow of the shell is determined by the output flow of the separator which is almost identical to it and after installation and definition of the separating tower and the formation of product flow from the bottom of tower, it will be connected to the converter's shell via a recursive logical operator to input flow. The recursive logical tool, unlike many operational devices, has no return computation. If the input current is removed from the operating state, there is no change in the output current. In other software tools and equipment's, when a parameter is changed for example the pressure of a flow in Petrosim, the

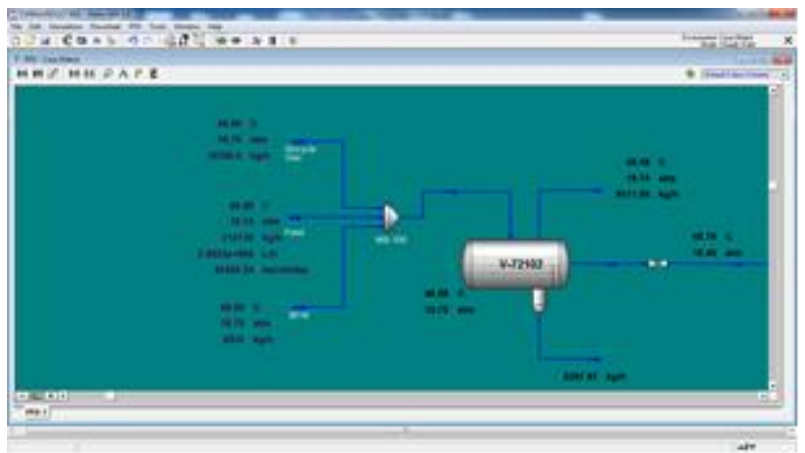

computation is automatically performed for all the involved parameters. These calculations take place in two steps. In the first step, the initial value is cleared and the flow is calculated with zero and then in the second step puts the new value in it and the calculations are done again and new values are obtained. However, the recursive logical operator is not similar to other tools and software equipment's. The output current of recursive operator will be copied to obtain acceptable error values from the input current [40].

Simulation of separating tower section of purification of Naphtha hydro treating unit

The output product of bottom of separating tower is entered into the separating tower as feed to separate light Naphtha of heavy Naphtha after cooling and pressure reduction. In order to simulate the tower first, the reflux flow and its Reboiler output current are determined by previous similar flows. Now from the palette simulation tool menu, the custom tower option is selected and On the homepage of the design section of the fittings it connects the input and output flows of tower and the number of the tower trays is 47 numbers and The tray number 26 is set as feed tray. High pressure of tower 1.22 relative bar and low pressure of tower is described 1.48 relative bar. Then, it implements the tower to converge its convergence.

From the output vapor flow of the top portion of tower equipment is installed according to the unit's technical documents. 
The light Naphtha flow is then connected with a complete reflux by the recursive logical operator to the pre-determined tower flow from the top of the tower input, and is accomplished by implementing its convergence tower. After that the mass flow current reflux will be specified 134 tons per hour till the rest of flow from the top of the tower will be defined as light Naphtha product to send into the isomerization unit. In order to simulate the equipment, belong to the bottom of the tower, the output flow of bottom of the tower is divided into two sections which a part of that is to exchange the heat with the furnace to supply energy and desired heat required from the bottom of tower and the other is the down heavy Naphtha product of the tower. First temperature 158 degrees centigrade for furnace output flow will be obtained by determining thermal load of $20000 \mathrm{kw}$ and it will be connected to the down tower input flow by recursive logical operator so the tower will be implemented to ensure its convergence. The striking point in this case is that the pressure of the furnace output current should be adjusted when tower input is equal to the bottom of the tower otherwise, the output flow temperature of the tower bottom will be got a big difference with the actual temperature and the tower convergence may also be problematic. According to documents and evidences relating to operational conditions and a process the flow temperature of bottom of the tower is controlled by 150 degrees centigrade. In order to make these conditions, the regulator logical operator is used to control the product temperature down of the tower. After installation of this operator, the tower has been removed from the convergence then tower will be implemented again by adjusting some parameters to converge the tower convergence. After convergence of tower the more matching of simulation with desired operational conditions will be achieved with proper settings and changes in the equipment parameters of this section.

Kinetic calibration of Naphtha conversion process reactions by module Rof-Sim

This module, which is in the Excel environment, is the software based on the kinetic models used to simulate the catalyst conversion unit.
Figure 4. Simulation of separating tower section of purification of Naphtha hydro treating unit

Figure 5. Simulation of separating tower section of purification of Naphtha hydro treating unit
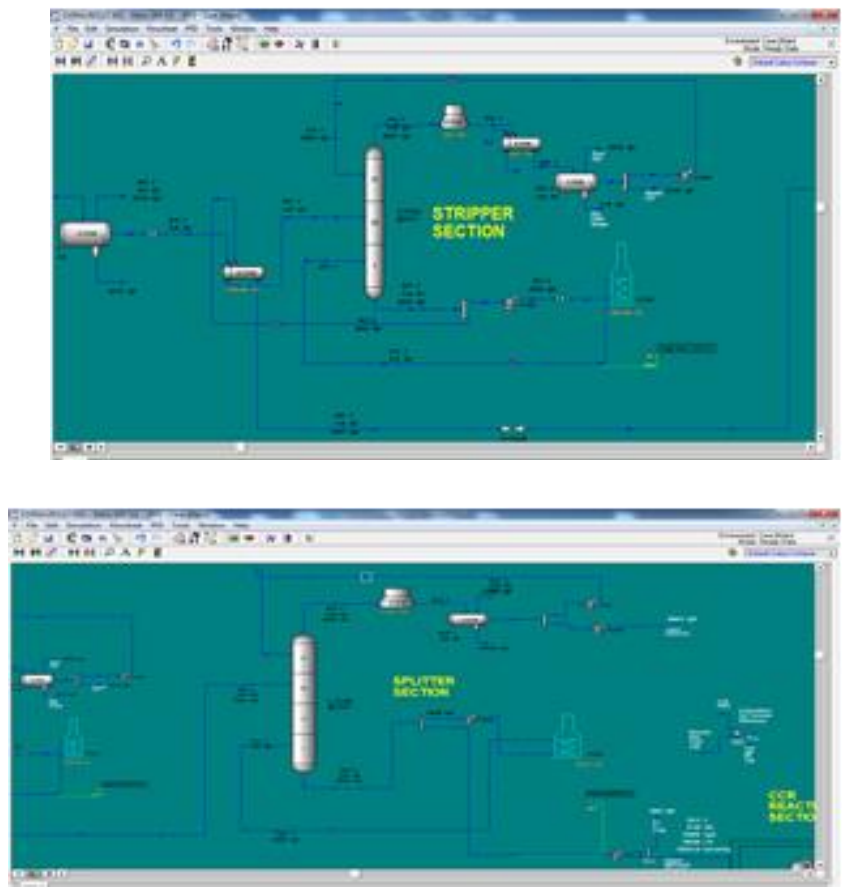
This module enables the user to simulate the unit and predict the yield of products within a wide range of operational conditions [41]. For calibration of this unit, a Rof-Sim module will be developed in Petrosim and the design page of this module will be completed first. The initial setting such as dimensions, unit design and the location of recursive hydrogen gas and other information will be specified in this page.

Examination the effect of capacity change of Naphtha catalytic conversion unit on the gasoline octane number and the amount of coke formed on the catalyst

This scenario has been investigated in terms of constant input temperature to the reactors at $525{ }^{\circ} \mathrm{C}$ and the constant rate of mass gas flow of 22 tons per hour with $90 \%$ purity and the constant mass flow of catalyst for 724 kilo gram per hour. Before starting, the gas returned flow must be regulated and recorded with the definition of logical function (ADJ) 22 tons per hour in all conditions. In this trial, the heavy purification Naphtha mass flow of catalytic conversion unit input feed with continuous revival has been considered as an independent variable for the unit capacity that will be changed in the range of 90000 to 170000 kilo gram per hour. The amount of produced gasoline octane number and the amount of coke formed percentage on the catalyst surface are also dependent variables. It should be noted that the amount of coke formed percentage allowed range on the catalyst surface is based on the capacity of coke unit of catalyst resuscitation ranging from 3 to $7 \%$. This range is a constraining factor in the operational condition for the amount of coke allowed.

Figure 6. Introduction and creation of Rof-Sim catalytic conversion module in Petrosim simulator

Figure 7. Design page of Naphtha catalytic conversion

Figure 8. Simulation of oil liquid gas recovery and reformate stabilization tower of Naphtha catalytic conversion unit with continuous revival
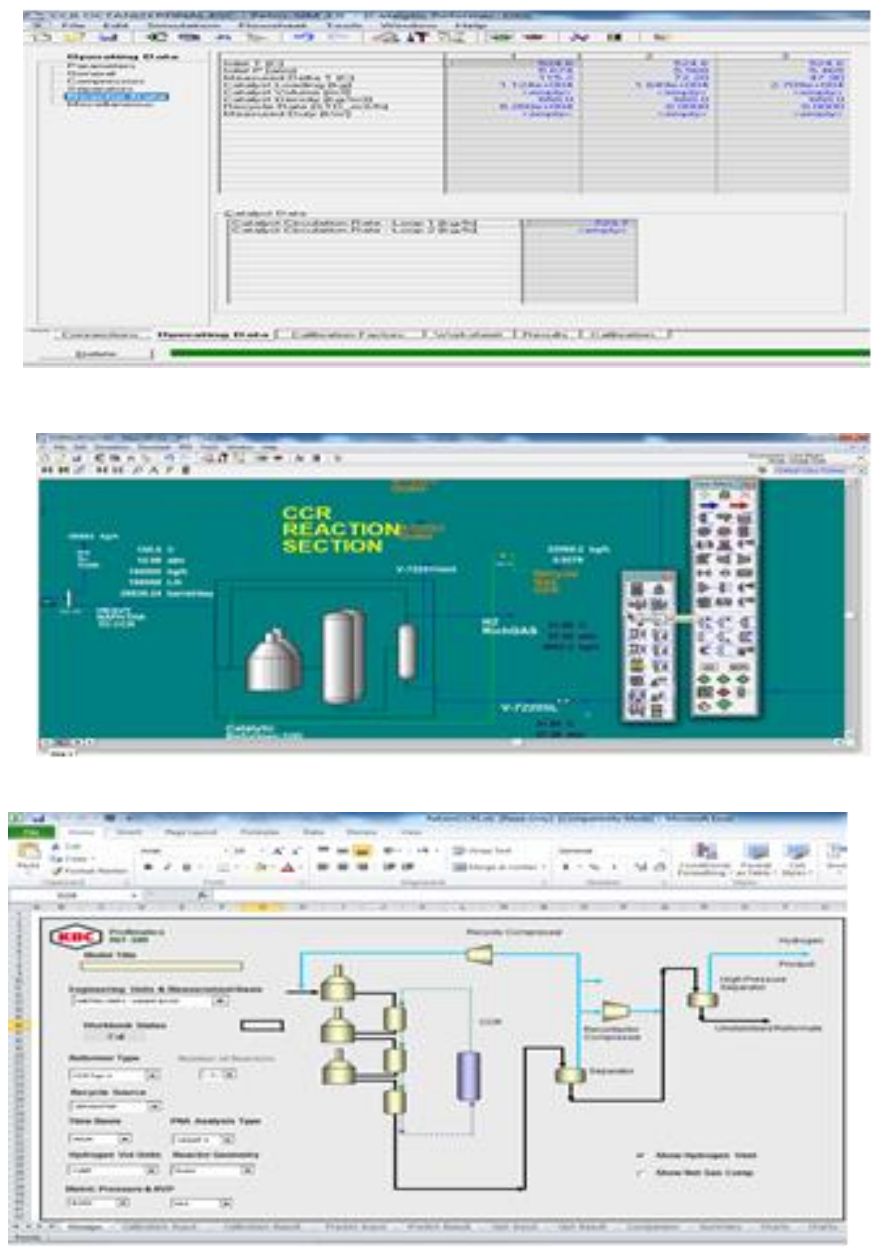
Figure 9. Effect of the catalytic conversion unit capacity changes on gasoline octane number and the amount of coke formed percentage on catalyst

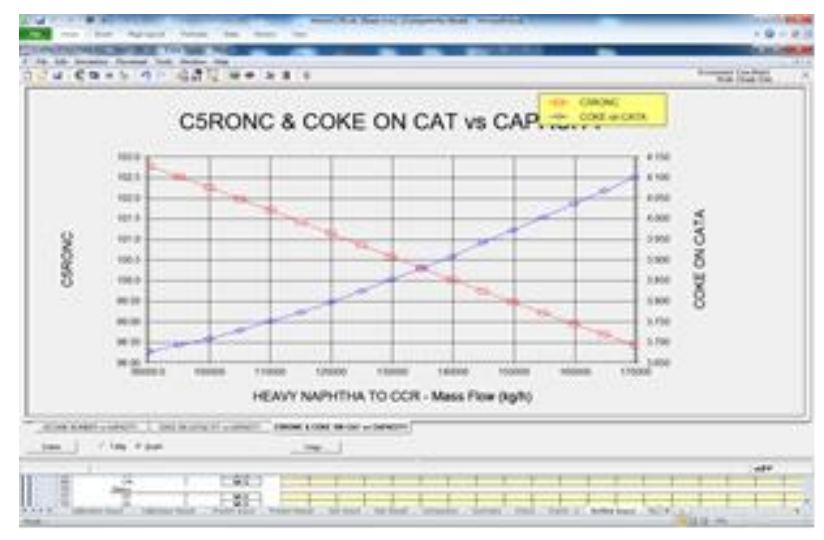

Table 3. The numerical values resulted from the effect of changing the catalytic conversion unit capacity on gasoline octane number and the amount of coke formed percentage on catalyst

\begin{tabular}{|c|c|c|}
\hline (Kg/hr) Unit capacity & Octane Number & $\begin{array}{l}\text { The percentage of coke formed on the } \\
\text { catalyst surface }\end{array}$ \\
\hline 90000 & 102.8 & 3.678 \\
\hline 95000 & 102.5 & 3.669 \\
\hline 100000 & 102.3 & 3.709 \\
\hline 105000 & 102 & 3.729 \\
\hline 110000 & 101.7 & 3.750 \\
\hline 115000 & 101.4 & 3.773 \\
\hline 120000 & 101.1 & 3.798 \\
\hline 125000 & 100.9 & 3.824 \\
\hline 130000 & 100.6 & 3.852 \\
\hline 135000 & 100.3 & 3.879 \\
\hline 140000 & 100 & 3.907 \\
\hline 145000 & 99.74 & 3.942 \\
\hline 150000 & 99.47 & 3.973 \\
\hline 155000 & 99.21 & 4.004 \\
\hline 160000 & 98.95 & 4.036 \\
\hline 165000 & 98.69 & 4.068 \\
\hline 170000 & 98.44 & 4.101 \\
\hline
\end{tabular}

As can be seen from Figure 9, by increasing the catalyst conversion unit capacity, the gasoline octane number conversion unit will be decreased and the amount of coke formed percentage on catalyst surface unit will be increased. But, in this variation of unit capacity, the percentage of coke formed is within the permitted range.
Investigation the input temperature of catalytic conversion unit reactors efficiency on octane number and the amount of coke formed on the catalyst

Due to the importance of the input temperature to the reactors in the catalyst conversion process, sensitivity analysis was 
performed to change the input temperature to the reactors on the octane number and the amount of coke production. This state is examined at a constant capacity 150000 kilo gram per hour equivalent to 30113 barrels per day of predicated heavy Naphtha feed, which is the catalytic conversion unit of Naphtha nominal capacity and a constant mass flow rate of 22 tons per hour of hydrogen gas, and the mass constant flow of catalyst equivalent to 724 kilo gram per hour. The reactors input temperature as a most important factors on octane number has been considered as an independent variable and also, gasoline product octane number and the amount of coke formed percentage on the catalyst surface as the dependent variable.

One of the important results of above figure is that the maximum permitted temperature of reactors input is $\mathbf{5 5 0}$ degrees centigrade. At warmer temperatures, positive dehydrogenation reactions tend to be more likely to negative hydrocracking reactions and their octane number not only changes but also decreases. As it is clear, the gasoline octane number will be increased by increasing the reactors temperature and the amount of coke formed, too. The slope of this coke formation increases dramatically at $520{ }^{\circ} \mathrm{C}$, which is problematic, and is the limiting factor for temperature rise. The main desirable and effective reactions on octane number rise are endothermic process such as dehydrogenation of Naphthenes, isomerization of paraffin's and Naphthenes and carbonization of paraffin's by dehydrogenation and will be intensify by temperature increasing and pressure decreasing. Also velocity of these reactions will kinematic be increased by temperature increasing. As shown in Figure 10, the activation energy of the reactions is related to the gradient of the diagram. The greater the gradient of the graph, the higher the activation energy and consequently, the increase in temperature will have a greater impact on the speed of the reaction such as carbonization of paraffin's which have high activation energy (about 35 kilo calories per mole) then temperature will increase this reaction rate. Hydrocracking reactions and coke formation have higher activation energy (35 and 45 kilo calories per mole). The velocity of these undesirable reactions is noticeable by temperature rise. According to the literature, the steep slope of coke increasing seems to be logical as the temperature rises. According to the obtained results and maximum allowed coke and desirable octane number in this study, the optimal input temperature of the catalytic conversion reactors at these conditions and capacity is obtained 150000 kilo gram per hour and in the range of 525 to 530 degrees centigrade. The reactor input temperature and catalyst velocity flow in different capacities must be how the octane number will be a constant rate 99 and the amount of coke formation in all conditions 0.5 percent.

Figure 10. Effect of input temperature changing of the catalytic conversion unit on gasoline octane number and the amount of coke formed percentage on catalyst

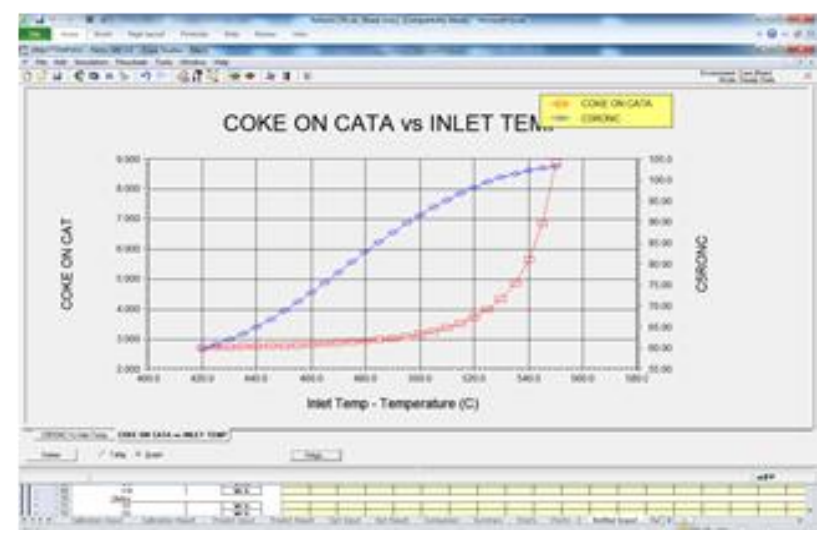


Figure 11. The obtained diagram of reactors input temperature and velocity of catalyst flow in various capacities how the octane number will be a fixed rate 99 and the rate of coke formed percentage 3.5 percent in all conditions

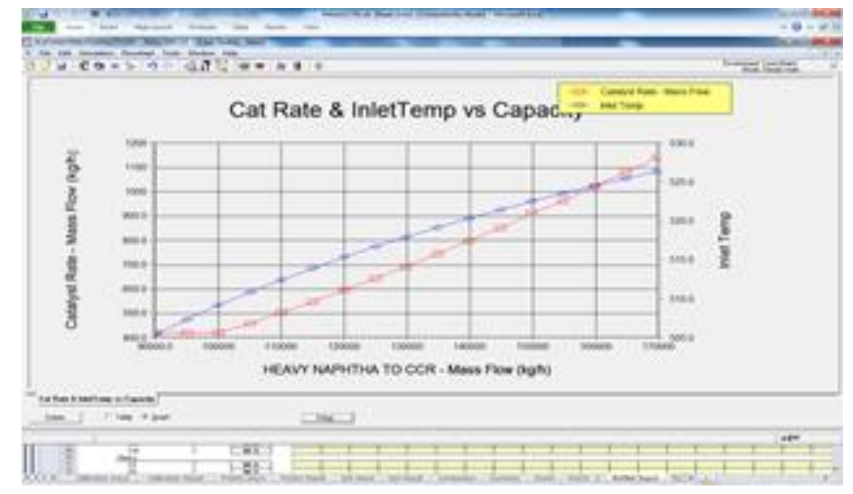

One of the most functional and practical issues that is required for the use of catalytic conversion unit of continuous resuscitation is this scenario. It is mainly due to various reasons and conditions that the unit operating in different capacities will have to produce gasoline with the required octane number. On the other hand, due to the settings and limitations of the coke and catalyst reduction, the percentage of coke formed should also be fixed and specified. The results of this study can play an effective role in controlling and the right and proper regulation of mentioned operational unit. The fixed condition of this scenario is the coke formed percentage equivalent to 3.5 percent and product gasoline octane number 99 and the rate of returned hydrogen gas mass flow with a purity of 90 percent has been considered 22 tons per hour. In this study the predicated heavy Naphtha mass flow input feed of catalytic conversion unit with continuous resuscitation has been considered as an independent variable for unit capacity which is changed in a range from 90000 to 170000 kilo gram per hour. The finding values of dependent variables which are the main purpose of this issue to regulate and control the operational unit, are reactors input temperature and rate of catalyst mass flow. The amount of coke formed percentage depends on different parameters and factors such as unit capacity, reactors input temperature, velocity of catalyst circulation flow, purity of returned hydrogen gas, portion of hydrogen to hydrocarbons and input reactors pressure. Among the mentioned factors, the most effective factor in this scenario can be applied to regulate and stabilize the coke formed percentage by changing on it, is the velocity of continuous catalytic conversion unit. The variable compliance of coke formation rate is an inverse ratio in relation to the parameter catalyst circulation flow. The higher the catalyst circulation flow rate, the lower the percentage of formed coke but due to increasing the velocity of the catalyst circulation flow, the possibility of the erosion and decrease of the useful life of the catalyst will be decreased by erosion increasing.

Investigation of the effect of catalyst circulation flow changes on the rate of coke formed on catalyst

According to the importance of controlling the rate of coke formed at nominal capacity of 150000 kilo gram per hour to complete the required information of previous scenario, it was necessary to investigate the effect of catalyst circulation flow on the rate of coke formed at this capacity and condition of returned hydrogen gas rate 22 tons per hour with the purity of 90 percent and a constant temperature of 525 degrees centigrade at the reactor entrance. The proper range for catalyst circulation flow is from 600 to 1200 kilo gram per hour. The higher flow will be resulted in more erosion and catalyst useful life decreasing. In this study, the independent variable is catalyst circulation mass flow which has been specified by a flow definition 
and mass flow rate as this trial input and the rate of coke formed percentage is the dependent variable.

As seen in Figure 12 and 13, can be found out the optimum reactors input temperature is 525 degrees centigrade because they can produce gasoline with octane number 100 for nominal capacity 30000 barrels per day of catalytic conversion unit, also they will be contained more ranges of various and functional capacities to produce gasoline with octane number 100 and this temperature also has maximum capacity of 170 tons per hour to produce gasoline with octane number 98.6 where it can be achieved the gasoline with octane number 100 by applying partial changes such as increasing temperature of bottom of stabilizer tower of catalyst conversion unit or increasing portion of hydrogen to hydrocarbon or partial increasing of reactors input pressure.

Investigation of the effect of reactors input temperature changes on volumetric yield rate and product of gasoline octane number

One of the important parameters which is used for increasing temperature to improve the octane number is the percentage of volumetric yield rate of gasoline that plays a prominent role to determine the maximum allowable reactors input temperature. Volumetric yield in the catalytic conversion process is the volumetric ratio of product to feed. The aim of this study is to continue detection of limiting and effective factors on increasing the gasoline octane number process to find optimal operating conditions. This study has been conducted at the constant capacity 137 tons per hour of predicated heavy Naphtha feed equivalent to 27500 barrels per day and constant flow 724 kilo gram per hour of catalyst circulation. The reactors input temperature has been independent variable and the percentage of volumetric yield and gasoline octane number have been dependent variable.

Figure 12. Investigation the effect of catalyst circulation flow changing on the rate of coke formed percentage on catalyst results in the constant capacity 30000 barrels/day

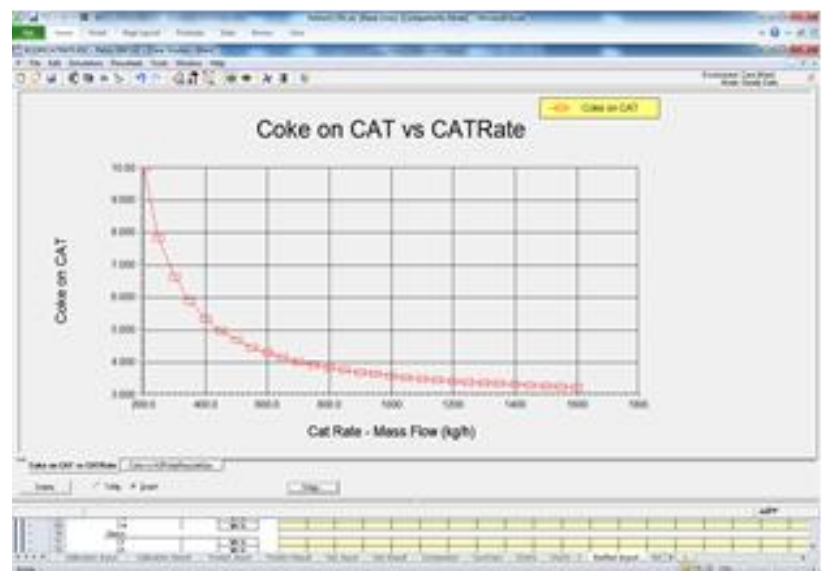

Figure 13. The results of the simultaneous impact of reactors input temperature changes and unit capacity on the gasoline octane number

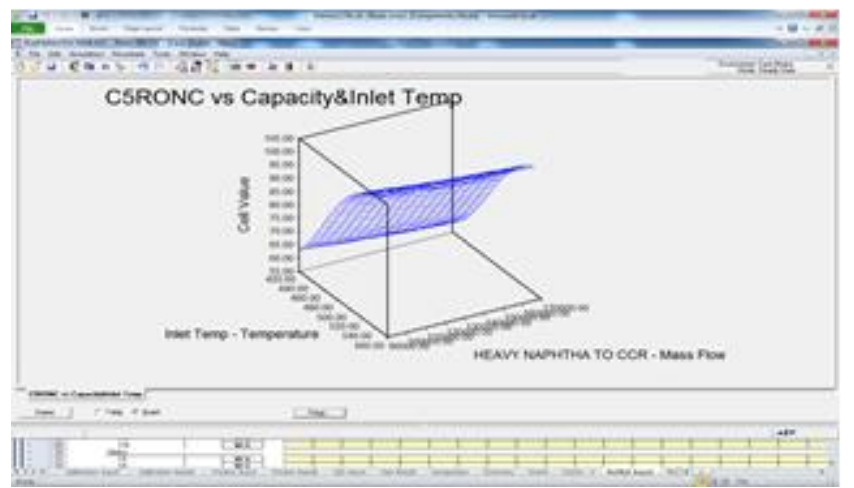


Figure 14. The results of reactors input temperature efficiency results on volumetric yield rate and gasoline octane number

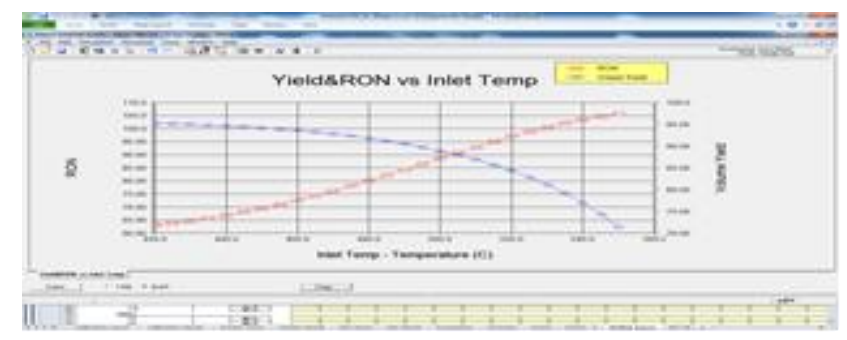

The investigation and observation of results indicated that product volumetric efficiency is reduced in exchange for increasing the reactors input temperature. As mentioned before, because of high activation energy required for hydrocracking reactions, the velocity of this undesirable reactions have dramatically increased by temperature increasing and the bigger molecules has converted to smaller ones due to hydrogen deficiency then the percentage of gasoline volumetric yield rate will be decreased by increasing the production of lighter products such as oil liquid-based gas.

Investigation of the effect of Naphtha catalytic conversion unit capacity changes on gasoline octane number and the rate of coke formed on catalyst

According Figures 15 and 16 one of the most important results of this study is that the reactors input maximum permitted temperature is equal to 550 degrees centigrade. The main obtained result is that gasoline octane number will be increased by increasing the reactors temperature but the rate of coke formed will be increased, too. The slop of this coke formation will dramatically increase up to 520 degrees centigrade which will be problematic and is the temperature limiting factor. Thus the reactor optimal input temperature of catalytic conversion will obtain in the condition of constant capacity 150000 kilo gram per hour of purification heavy Naphtha feed of catalytic conversion unit and constant mass flow 22 tons per hour of returned hydrogen gas with $90 \%$ purity and constant catalyst circulation mass flow 724 kilo gram per hour in the range of 525 to 530 degrees centigrade.

Investigation the impact of catalyst circulation flow changes on the percentage rate of coke formed on catalyst

In the nominal capacity 150 tons per hour and in the condition of returned hydrogen gas rate 22 tons per hour with $90 \%$ purity and constant temperature 525 degrees centigrade of reactors input, in the range of 600 to 1200 $\mathrm{kg} / \mathrm{hr}$ of catalyst circulation mass flow, this study has been investigated. The important result of this study is that the percentage rate of coke formed on catalyst will be decreased by increasing the catalyst circulation mass flow and the flow 800 kilo gram per hour of catalyst circulation will be proper for nominal capacity 150 tons per hour with specified process conditions to regulate and control 3.8 percent of coke formed.

Investigation the impact of reactors input temperature on volumetric yield rate and gasoline octane number

This study has been investigated in the condition of constant capacity 137 tons per hour of purificated heavy Naphtha feed equivalent to 27500 barrels per day and constant flow 724 kilo gram per hour of catalyst circulation. Investigation and observation the obtained results indicate product volumetric yield decreasing by reactors input temperature increasing. According to volumetric yield rate and considering gasoline octane number, the reactors optimal input temperature of catalytic conversion is in the range of 520 to 
535 degrees centigrade based on the specified conditions which causes volumetric yield 84

Figure 15. CCR Schemes

Figure 16. OCT Schemes

\section{Conclusion}

One of the most important process in refineries is Naphtha catalytic conversion. In this process, gasoline with high octane number produce in the petrochemical complexes of precious aromatics such as benzene, toluene and xylene. Due to the importance of fuel and its more production of initial oil materials and the optimization possibility and catalytic reactor performance improvement in order to increasing the quality and quantity of products, the necessity of simulation and investigation the involved parameters and its performance improvement will be necessary. This process contains three numbers radial flow reactors, to 79 percent.
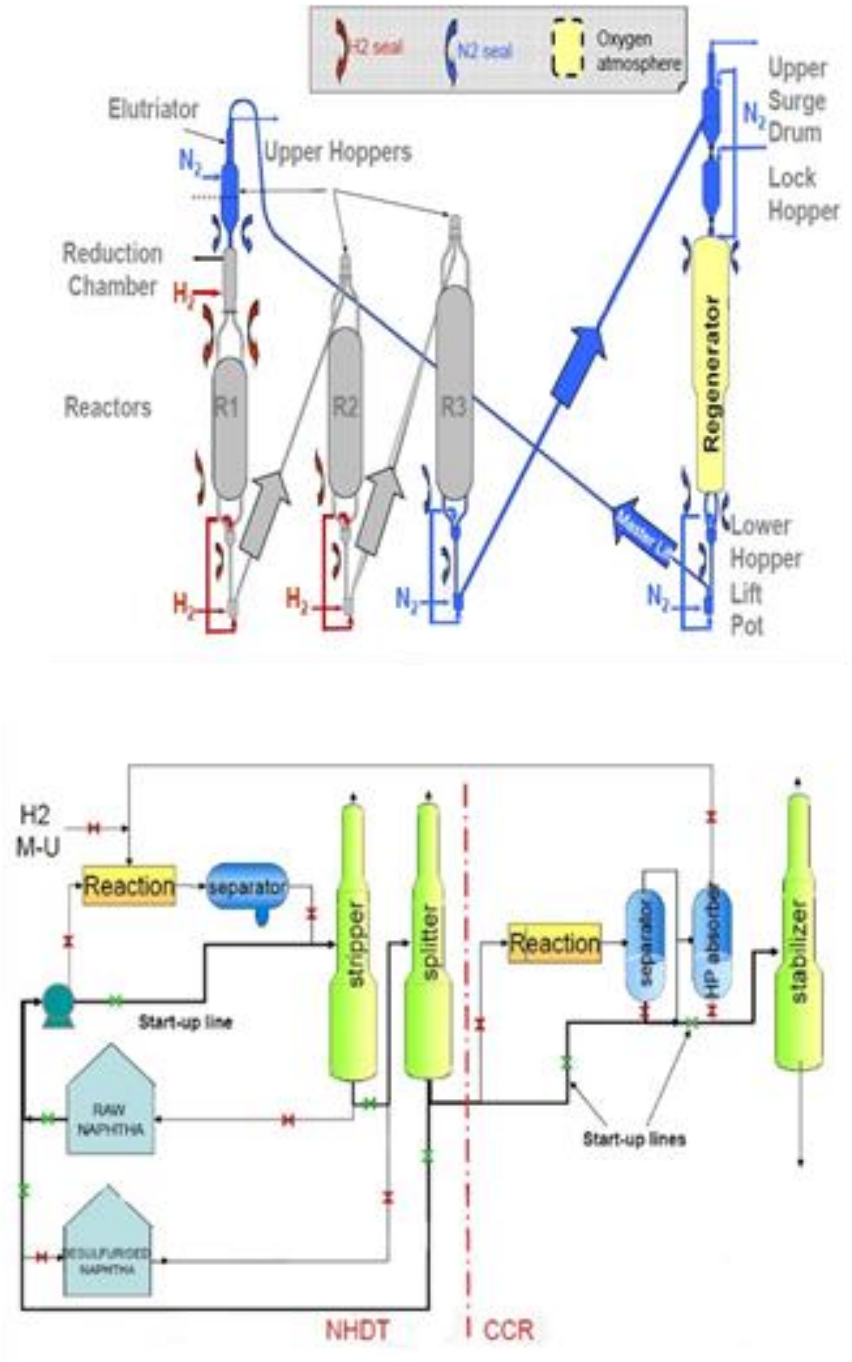

furnace, a separator tank, some thermal conversion and a compressor which has been done more than 300 reactions in these reactors that should be use the presented kinetics models for simulation. In the refinery, the input temperature of the three reactors is same that the catalyst will gradually be inactive, the reactors input temperature will increase with respect to product quality analysis. Also, the input features feed changes and its flow rate fluctuations will effect on products distribution and octane number then will make it unstable. It should be noted that if the percentage of compounds and the values of distilled feed of purificated Naphtha unit changed, the recommended operational 
values and unit process conditions will be changed. Using the overall results of all surveys, the best values of operational variables to control and regulate the unit process condition of catalytic conversion unit in nominal capacity 150 tons to obtain the gasoline maximum yield with octane number 100 recommend as follow: by choosing the temperature 525 degrees centigrade of reactors input, flow 22 tons per hour circulating gas, flow 800 kilo gram per hour of catalyst circulation, pressure 5.5 relative bar of compressor circulation output gas, concentration 0.9 weight percentage of catalyst chloride, temperature 261 degrees centigrade and pressure 15.7 output relative bar of stabilizer tower Reboiler and temperature 155 degrees centigrade and pressure 1.5 relative bar of the end of separator tower of purificated Naphtha hydrogenation unit to bring the initial boiling point of heavy Naphtha feed to the optimal temperature 107 degrees centigrade, gasoline with mass flow 140525 kilo gram per hour equal to 25630 barrels per day with octane number 100 and 0.37 volumetric percentage benzene has been produced that mass yield of catalytic conversion unit 94 percent and volumetric yield 86 percent has been calculated. In these conditions, the rate of coke formed 3.64 percent, purity of hydrogen circulating gas 93 percent, molar ratio $\frac{\mathbf{H}_{2}}{\mathbf{C H}} 2.7$ and the reactors furnaces whole consumed energy 105500 kilo watt will be obtained.

\section{Acknowledgement}

The study is part of a Thesis of Amir Samimi (Ph.D. student of science in chemical engineering, Islamic Azad University, Mahshahr, Iran).

\section{Disclosure statement}

No potential conflict of interest was reported by the authors.

\section{ORCID}

A. Samimi (D: $\underline{0000-0001-7270-2261}$

\section{Reference}

[1] T. Lan, Y. Zhang, C. Jiang, G. Yang, Z. Zhao, J. Atmosphere. Solar-Terrest. Phys., 2018, 179, 389-395.

[2] I. Davood, K. Mohsen, A. Shahram, J. Mitra, R. Razieh, R. Mohamad, Chem. Eng. Res. Des., 2014, 92, 1704-1727.

[3] K. Khalili-Damghani, F. Abdi, S. Abolmakarem, Appl. Soft Comput., 2018, 73, 816-828.

[4] G. Zhou, L. Wang, Transp. Res. Part C Emerg., 2012, 21, 287-305.

[5] F.V. Barsi, D. Cardoso, Braz. J. Chem. Eng., 2009, 26, 353-360.

[6] L. Wang, Q. Li, Y. Yu, J. Liu, Expert Syst. Appl., 2018, 105, 112-128

[7] I. Marton, A. Sánchezb, S. Carlos, S. Martorell, Chem. Eng. Trans, 2013, 33, 301-306.

[8] E. Mazloumi, G. Rose, G. Currie, S. Moridpour, Eng. Appl. Artif. Intell. 2011, 24, 534-542.

[9] (a) S. Mohammadi, A. Taheri, Z. Rezayatizad, Prog. Chem. Biochem. Res., 2018, 1, 110; (b) S. Sajjadifar, Z. Arzehgar, A. Ghayuri, J. Chin. Chem. Soc., 2018, 65, 205-211.

[10] E. Mazloumi, G. Rose, G. Currie, S. Moridpour, Eng. Appl. Artif. Intell., 2011, 24, 534-542.

[11] T. Varga, F. Szeifert, J. Abonyi, Eng. Appl. Artif. Intell., 2009, 22, 569-578.

[12] H. OH., W.S. SEO., Jpn. J. Nurs. Sci.. 2012, 124, 110-121.

[13]M. Gyngazova, A.V. Kravtsor, E.D. Ivanchina, M.R. Korolenko, D.D. Uvarkina, Catal. Ind., 2012, 2, 117-128.

[14] H. Weifeng, S. Hongye, M.U. Shengjing, C.H.U. Jian, Chin. J. Chem. Eng., 2007, 15, 75-80.

[15] M.S. Gyngazova, N.V. Chekantsev, M.V. Korolenko, E.D. Ivanchina, A.V. Kravtsov, 
Catal. Ind., 2012, 4, 284-291.

[16] D. Iranshah, M. Karimi, S. Amiri, M. Jafari, R. Rafiei, M. Rahimpour, Chem. Eng. Res. Design, 2014, 92, 1704-1727.

[17] M.Z. Stijepovic, A. Vojvodic-Ostojic, I. Milenkovic, P. Linke, Energ. Fuel., 2009, 23, 979-983.

[18] R.E. Palmer, S.H. Kao, C. Tong, D.R. Shipman, Hydrocarbon process., 2008, 55-66.

[19] A. Samimi, S. Zarinabadi, A. Shahbazi, A. Azimi, M. Mirzaei, J. Chem. Rev., 2019, 1, 154-163.

[20] S.A. Anatolevich, B.S. Michailovich, Chem. Methodol., 2019, 1, 12-29.

[21] S. Houshmandynia, R. Raked, F. Golbabaei, Chem. Methodol., 2018, 2, 324-332.

[22] H. Shafiee, F. Mostaghni, K. Ejraei, Chem. Methodol., 2018, 2, 114-127.

[23] O. Ghasemi, N. Mehrdadi, M. Baghdadi, B. Aminzadeh, Iran. Chem. Commun., 2019, 7, 352-367.

[24] G. Mansouri, M. Ghobadi, Iran. Chem. Commun., 2019, 7, 424-431.

[25] S.M. Habibi-Khorassani, M. Dehdab, M. Darijani, Iran. Chem. Commun., 2019, 7, 455-471.

[26] F. Fayyaz Jorshari, M. Rabbani, R. Rahimi, M. Rassa, Iran. Chem. Commun., 2019, 7, 53-62.

[27] G. Taoufiq, V. Dua, Comput. Chem. Eng., 2011, 35, 1838-1856.

[28] R. Motamedi, F. Ebrahimi, G. Rezanejade Bardajee, Asian J. Green Chem., 2019, 3, 22-33.

[29] S. Sajjadifar, I. Amini, H. Jabbari, 0. Pouralimardan, M.H. Fekri, K. Pal, Iran. Chem. Commun., 2019, 7, 191-199.

[30] M. Stijepovic, A. Ostojic, I. Milenkovic, P. Linke, Energ. Fuel, 2009, 23, 979-983.
[31] L. Nagarapu, M. Baseeruddin, S. Apuri, S. Kantevari, Catal. Commun., 2007, 8, 1729-1734.

[32] (a) M. Kooti, M. Karimi, E. Nasiri, J. Nanopart. Res., 2018, 20, 16; (b) Z. Arzehgar, S. Sajjadifar, H. Arandiyan, Asian J. Green Chem., 2019, 3, 43-52; (c) M. Shiri, M.M. Heravi, H. Hamidi, M.A. Zolfigol, Z. Tanbakouchian, A. Nejatinezhad-Arani, S.A. Shintre, N.A. Koorbanally, J. Iran. Chem. Soci., 2016, 13, 2239-2246.

[33] A. Samimi, S. Zarinabadi, A. Shahbazi, A. Azimi, M. Mirzaei, J. Med. Chem. Sci., 2020, 3, 79-94.

[34] M. Fattahi, A. Davoodnia, M. Pordel, Russ. J. Gen. Chem., 2017, 87, 863-867.

[35] A. Nakhaei, A. Davoodnia, S. Yadegarian, Iran. Chem. Commun., 2018, 6, 334-345.

[36] E. Teymooria, A. Davoodnia, A. Khojastehnezhad, N. Hosseininasab, Iran. Chem. Commun., 2019, 7, 271-282.

[37] (a) A.N. Egorochkin, O.V. Kuznetsova, N.M. Khamaletdinova, L.G. DomratchevaLvova, Inorganica Chim. Acta, 2018, 471, 148-158; (b) S. Sajjadifar, I. Amini; T. Amoozadeh, Chem. Methodol., 2017, 1, 111; (c) M.M. Heravi, H. Hamidi, N. Karimi, A. Amouchi, Adv. J. Chem. A, 2018, 1, 1-6.

[38] M.H. Fekri, A. Omrani, S. Jamehbozorgi, M. Razavi mehr, Adv. J. Chem. A, 2019, 2, 1420.

[39] R. Ghiasi, A. Heydarbeighi, Russian J. Inorg. Chem., 2016, 61, 985-992.

[40] (a) G.S. Nirmala, L. Muruganandam, J. Chem. Rev., 2019, 1, 114-129; (b) S. Sajjadifar, H. Hamidi, K. Pal, 2019, J. Chem. Rev., 1, 35-46.

[41] A. Samimi, S. Zarinabadi, A. Shahbazi, A. Azimi, M. Mirzaei, Iran. Chem. Commun., 2019, 7,681-691.

How to cite this manuscript: Amir Samimi, Soroush Zarinabadi, Amir Hossein Shahbazi Kootenaei, Alireza Azimi, Masoumeh Mirzaei, Optimization of Naphtha Hydro-Threating Unit with Continuous Resuscitation Due to the Optimum Temperature of Octanizer Unit Reactors, Adv. J. Chem. A, 2020, 3(2), 165-180. 